\title{
The top layers of water bodies, a most important although relatively neglected piece of the biosphere plumbing*
}

\author{
RAMÓN MARGALEF \\ Departament d'Ecologia, Facultat de Biologia, Universitat de Barcelona, Diagonal 645, 08028 Barcelona, Spain.
}

\begin{abstract}
SUMMARY: Reducing power from light is used by plant life in ways that shift along ecological succession. When nutrients are non limiting, growth prevails; when essential nutrients (in the first place P) become scarce, reducing power is applied somehow and otherwise, often, as in red tides, in the synthesis of toxics. On land, the same reducing capacity results in the production of wood, terpenes, essences, cork or rubber. In water bodies, reduction of nitrate at least adds nitrite to the environment. Very likely this explains the common presence of nitrite-enriched layers around the levels of twilight. A large fraction of the generating capacity might be expected to come from the small prokaryota of phytoplankton, which almost global ubiquity and capacity to persist alive in a state of forced minimal activity are known. The result might be a kind of one-way plankton surface valve, that isolates partially and in some chemical aspects the deeper ocean from the top layers. One could perhaps speak of a surface valve with a planetary role.
\end{abstract}

Key words: picoplankton, light reducing power, nitrite, ocean surface valve, dinoflagellates, coccolithophorides, Western Mediterranean

I feel immensely grateful to friends and colleagues for their very special invitation to attend this meeting. For me it is like a lease on my scientific life, and I will profit of this privilege for expressing myself freely, also in the hope of benefiting from new instruction that could clarify what have been for me, and still in part are, persistent problems.

My subject now concerns the functional structure of the surperficial layers of the water bodies -and specifically of the oceans. My feeling is that the rich degree of organization at a small scale of the top layers of the oceans, and their dynamics, isolates very effectively and in a rather complex way the atmosphere from the larger mass of ocean waters. Now there are possible new approaches to old problems, although many doubts remain. The relatively recent

*Received February 15, 2001. Accepted March 20, 2001. recognition of the omnipresence of very small prokaryota, forces any phytoplankton student to reconsider the classical views. The indefinite -even close to "eternal"- vitality of such small things, associated with their capacity to generate reducing power, and their "unsinkability", explains their presence in important and potentially very active layers of the hydrosphere. I am asking myself if the generated kind of situations might be compared, from a global point of view (could I dare to write Gaia's point of view?), to those that prevail on land.

Plankton communities get reducing power from light and apply it to grow biological organization. The very tiny things for which planktonologists did not care sufficiently until now, are responsible for the creation and maintenance of a sort of "plankton surface valve" effective in controlling gas exchanges with the atmosphere. I remember having discussed 
this aspect with Richard Vollenweider many years ago, in relation with lakes and reservoirs, but the validity of the same mechanism in the oceans was not clear to me until recently, when the life and activity of a large number of tiny, pigmented cells, apt to persist inactive in some kind of "suspended animation" became obvious to the students of plankton, as a last or at least penultimate stage in the gradual recognition of small and smaller living elements suspended in water and practically immortal through periods of suspended activity.

The quality of being virtually unsinkable matters very much through providing a background quality that "colours" potentially and uniformly a mass of water, to which it confers some reducing power, small or large. I will keep insisting in the very important fact that the smallness of the organisms under consideration bounds them almost solidly to water, in the sense that active or passive, such tiny beasts do not sink naturally or, at least, they should move downwards with extreme slowness. Again, their smallness assures their ubiquitous availability at every level and their perpetual and universal effectivity as potential providers of reducing power.

These small organisms absorb radiation and make available reducing power everywhere. Phosphorus is necessary for biosynthesis, and most generally its scarcity is the factor that sets limits to the grow of "real" life. If phosphorus is no more available, light reaching the photosynthetic system results in the generation of extra chemical reducing power that could be put to varied uses, significant in survival and evolution, even if some of their supposed functions might appear not essential or only secondarily helpful in competition.

A good argument in favour of this assertion may start considering the role played by wood in terrestrial ecosystems, best expressed in the success of the tree as dominant life-form on land. This could led immediately to suspect some possible utility or positive effect of the reducing power of picoplankton -and also of phytoplankton of larger size, if nutrients (read, mainly, phosphorus!) are only minimally available. To be sure, besides wood leading to occupation and use of space and to historical persistence, reducing power available on land provides further for synthesis of a large spectrum of helpful materials, from essences to cork and rubber. I think that through such kind of considerations we could be better prepared to grasp more adequately any important role for the most tiny organisms suspended in sea water.
I think in special of dinoflagellates and of their toxic secretions, that in their variety can be compared with the variety of essences, volatiles, gums, etc. produced by terrestrial plants. It is a new world of static and quiescent material organizations and their ancillary products that not only dissolve in water, but can pass to the atmosphere, as it is recorded that happens in patches above dinoflagellate and coccolithophore blooms, and that can be compared to the essences produced by terrestrial plants, or that can be operative by ingestion, like the many kinds of poisons produced principally, but not exclusively, by dinoflagellates, substances that in a further step, led to resistance to them or mithridatism. Indeed mussels absorbe poisons, that only later become dangerously effective in humans eating them. Speculation wanders freely and phantasy can go ahead many steps. I spent a considerable fraction of time in my life counting plankton samples, although now I feel that the results were barely worth of the effort. In the first place, we used an inadequate fixing fluid with iodide and formaline that destroyed coccoliths badly. They became under- represented in our lists, as the recent and careful study by Lluisa Cros (2001) shows (her Ph D thesis, recently sustained). Coccolithophores seem to be involved in the job of using excess reducing power to produce several compounds, suspected at least to go to the atmosphere and perhaps exploited as to signal to marine birds the probability of finding some source of fish meat. Fish could eat plankton, so the trick would tend to reduce the number of local enemies. It might appear a bit convoluted to be true, but so has been said.

I would suspect that the oceans provide convincing scenarios for the evolution of comparable mechanisms. As stated before, dinoflagellates -as well as organisms of other taxonomic groups-, towards the end of their blooms (red tides), when available phosphorus becomes scarce in water, produce a large variety of toxic molecules consisting of hydrocarbon chains, as it could be anticipated, without phosphorus, apt to kill and initiate the decomposition of varied organisms of different taxonomic groups, thus recycling and making available again elements that were disappearing from the liquid environment, probably phosphorus in the first place of importance. Such events contribute, among others, to increase diversification in oceanic life.

The basics concern the importance of the role played in survival and evolution by the reducing power gained by pigment bearing cyanobacteria, how effectively it is applied to inorganic -and organ- 
ic- compounds present at sea, and how such effectivity is reflected, and eventually could be estimated, first through the spectra of fluorescence emitted by pigment bearing microorganisms, and later and more obviously by their survival.

An important fraction of the excedent reducing power is probably invested in the reduction of nitrate to nitrite in the environment (Blasco, 1971). Although the layers enriched in nitrite in many places and seasons have been explained and interpreted in different ways, they have been accepted as common without much discussion, although they were seen often as intermediate stages in a process of fast recycling, "sparing energy" for the legion of organisms that are to take nitrogen compounds again. Now, after recognition of the ubiquity of small cells and their reducing power, as well as the coincidence of the very abundant populations of them with the levels of maximum nitrite, the immediate suggestion points to the importance of the role of such tiny cells in using the energy of light in form of reducing power, its application to nitrate and their contribution to the creation of the layers of maximum nitrite concentration, thus made dependent also on the efficiency of such diminutive organisms. Such layers cannot be only a result of the activity of the larger components of phytoplankton, although their contribution has to be considered as well, although never in exclusive terms. The reduction of nitrate to nitrite would happen at twilight, assuming that algae could outcompete further limits to the biological productivity of the oceans in the present times. A decreasing biological productivity may be one reason why now the depths are not as anoxic as could be suspected or expected. Anyway, it seems to me that the whole pack of heterogeneous layers placed around the level of light extinction, and including at least part of the layers rich in "immortal" chlorophyll bearing tiny things -again remember that their smallness warrants their practical quality of unsinkables-, should play a considerable role in the regulation of the regime of the whole oceans. Falkowsky could agree. This is in coincidence also with views expressed by Vollenweider in relation with problems concerning lake eutrophication.

The different contributions (both, from prokaryotes and from true planktonic algae) help to generate more or less complex layers, approximately extended horizontally. One important role for them is that they operate presumably as unidirectional valves, that might be effective, providing in some sense and in one way a relative isolation of the deep- er oceanic waters from the water layers closer to the surface, more illuminated and where the exchanges with the atmosphere are easy.

Obviously, differences in the behaviour of organisms of the different groups (diatoms and different flagellates; Lomas and Glibert, 2000) should be expected, and not only between prokaryota and eucaryota. Further interest in the problem could only reveal that the layer relatively rich in nitrite is generally not much thick, but it is present almost everywhere or in many different marine areas, and, as should be expected, shows particularly well in places where stratification of water has persisted recently for a while. The areas in which such layers are less thick or disappear altogether coincide, as expected, with places subjected to vertical mixing by reasons that have to do with water mechanics.

It could be suspected that around such kinds of distributions relevant phenomena exist, and perhaps now unsuspected mechanisms are added as special situations arise. Laboratory experiments by Dolors Blasco complemented the observations on layers relatively enriched in nitrite at sea. The environmental reduction of nitrate to nitrite, using mixed cultures under different conditions was studied by her (Blasco, 1971). Shifts in the chemical environmental through action of the organisms was evident, in part demonstrated by the apparent capacity of phytoplankton populations to take nitrate and excrete nitrite. There is a rather long history of research and speculation concerning this subject. Discussion especially centered around the possibility of some shortcut in the cycle of nitrogen, but now I do not want to go again in the subject, except in one aspect that might be relevant to my present interpretations and hypothesis.

The background scenario offered by the oceans differs from the one presented by the surface of continents, in what concerns the final use of the reducing power of the light, as made available through the machinery of photosynthesis, that essentially is the same everywhere. Reducing power seems to have seen applied perhaps much less at sea, or at least in a different way, perhaps less important, or this may be only apparent, as there does not exist the marine equivalent of wood and "true" forests, only a shore of reducing power. Or perhaps other competing mechanisms have been effective in evolution: In fact, rigid, strong, but passive material is not, could not be, perhaps for mechanical or other physical reasons, as successful in generating organisms mechanically successful in the open sea as it has been on 
land, except perhaps only on a relatively minor scale, as in few coastal algae, kelp and the floating communities of kelp and sargasso weeds -the mechanical problems are different, as in the sea large plants need to remain mechanically flexible. It seems that the forest and the plankton, as model ecosystems, have been forced along quite diverging paths in their separate evolution in diverging environments (Bates, 1960).

Although the scenarios on land and at sea might appear different, they are substantially comparable (Margalef, 1997). In the sea evolution has barely found uses for wood and cork, or for their analogues or equivalents, in the sense to create large complex molecules without phosphorus, but apt to add to the survival value of the organisms, as are mucilages, terpenes and essences in general. We do not know, for the time being, there might exist at sea some other equivalent ways to contribute to the organization and conservation of most ancient or primitive kinds of ecosystems

Recognition of the ubiquity of such kind of relations leads to wonder about the different ways in which the reducing power obtained from light in the photosynthetic system has been incorporated and put to work by life and evolution, both at sea as in the terrestrial ecosystem, in which it has been made historically more apparent to our species, at least in the role played by wood, rubber and many varied volatile hydrocarbons.

Cycles of nutrients are responsible for local segregations as well as for historical changes expressed as repeated ecological successions. I am grateful to destiny for having introduced me to the study of marine life in the Rias of Galicia, in NW Spain. I was much impressed by regular events of mixing of the water in the interior of the rias, that are relatively narrow inlets, penetrating deeply on land, which water is renovated by mixing with the outside ocean, in a more or less irregular and, at least, discontinuous way. Massive water exchanges reinitialize from time to time the development of populations that ordinarily start with the dominance of diatoms. Succession may end after a few weeks, a time that can be extended up to a couple of months, ending in red tides. To start again the process, always replaying the particular path converging also towards red tides again. Old local fishermen used to compare red tides to menstruation, as seen as a way for the sea of cleansing itself periodically, at least inside the rias. Anyway, the events are terminated in a more or less relatively discon- tinuous or sudden way by acceleration of the exchange of water between the rias and the Atlantic, an event, relatively rapid, that is always followed by a sharp change in the plankton quality, normally restarted with a dominance of diatoms.

I tried, although without total success by reason of technical limitations, to reproduce on rafts at sea such successional sequences. I was later more successful in the laboratory, continuing to experiment with cultures in enriched water, held circulating along plastic flexible and transparent tubes. After some trials, insistence was rewarded by more success in reproducing plankton successions and, with some surprise, I found as a general and repeatable event a shift in the composition of photosynthetic pigments, that I tried to characterize and express by the ratio between the absorptions of acetonic extracts at the respective wavelengths of 430 and $665 \mu \mathrm{m}$ (Margalef, 1958).

Although perhaps it is not essential to my present discourse, I would like to stress the pertinence of the concept of ecological succession and its analysis, in the frame of how one compound or mixed population follows another, in a way in which spatial heterogeneity is essentially generated by, or become associated with, such kind of successional changes, as expressed in the more or less advanced stages in patches of water that are representative of stages in a process of ecological succession. Populations never remain constant in their composition, but continuously shift as the result of differences in growth speed among the different species present and those that might become available in the course of time, or grow in relation with more fundamental (being the cause of change) shifts in the properties of the surrounding volumes of water. In this way, local differences are generated, and their relationship as well as their influence on the populations becomes traceably identified. Repeated ecological succession provides the scenario where persistent trends in selection can be expressed as one common scenario in which evolution becomes more a collective event than a bunch of haphazard adventures.

Out of the laboratory experiments, in the open seas, extensive and wider ranging gradients are observed, as they develop and appear or vanish under more or less strong mixing and expressing local trends. These may differ up to the point to generate relatively sharp discontinuities, that manifest themselves over larger volumes and become specially interesting when boundaries attract more attention for being more manifest. 
One could expect that vertical patterns (stratification) should be quite general, or at least provide for more expectable or more regular explanations, than differences expressed between points at the same level, in the form of horizontal patchiness. After all, vertical distributions have a number of determining and controlling factors of common and well known operation, as distribution of light, mechanical energy, nutrients, etc.

Besides considerations and experiments on the possible generation of gradients in the distributions of organisms, it soon became obvious that the phytoplankton reacts in its composition to the more or less complex structure and properties of the environment. After what has been written it is natural to consider the quality and distribution of phytoplankton in relation with the concentration of reduced nitrogen compounds (nitrite) in local patches or even amplified as large end even continuous layers, which in the Mediterranean are extended normally between 30 and 50 meters (occasionally going down to $70 \mathrm{~m}$ ) around twilight depths (Margalef et al., 1966; Margalef, 1995). Locally and notoriously, the levels of maximal fluorescence of phytoplankton; that is, of maximal return of radiation not used by photosynthesis, are found between 40 and $80 \mathrm{~m}$ depth and tend to coincide with levels where a recent reduction of nitrate to nitrite was probably intense, resulting in relatively high concentrations of nitrite $(50-380 \mathrm{ng}$ at/L) in the water at such levels.

There are not walls in the sea, and the patterns related to succession, or to stratification or either to shear of water masses, have open boundaries and have to be related to incompleted processes of mixing operating between centers of different chemical activity.

Now we begin to have more data -although never enough- concerning the same NW Mediterranean areas, and even experimental approaches, that make us more familiar with the life and distribution of beings much more tiny than coccolithophores, pigmented bacteria and cyanobacteria less or much less than $2 \mu \mathrm{m}$ across, and it seems obvious, or at least I am ready to accept, that such organisms in tremendous numbers (1000-200000 cels. per mL) and apt to persist, alive and relatively non active, for long periods of time, could be sensibly effective biochemically. What enthuses me is the virtual immortality of such tiny "beasts", their null or relatively low speed of sedimentation, and their availability everywhere, keeping their capacity to apply their undeniable reducing power when appropriate conditions presents themselves. This should happen over all the world ocean and, to me, Western Mediterranean could provide an excellent space for consideration. Recent work (Gasol and del Giorgio, 2000, and references there; Denis et al., 2000) provides numbers concerning our NW Mediterranean corner. More information from elsewhere is coming aplenty (see, for instance, papers from French authors concerning the tropical Pacific in J. Geophys. Res., 104: 3223-3422, 1999). An important question that could be asked concerns the true state and activity of every cell (Hagström, 1999).

I could add some information concerning the primary production of the NW Mediterranean area that, in general, for the average Mediterranean, is really high. Although the matter relates only indirectly to the present subject in this presentation, I would like to add that my views never were consistent with the frequently expressed hypotheses that "our" area of the formation during the cold season of surface water which density had been increased by strong evaporation under the effect of Western winds and then moved vertically downwards. In fact it is a rather windy region, and strong wind blows often from West to East, more or less in line with the axis of the Pyrenees, and happens to be particularly strong in winter. Such eastward atmospheric transportation along the Pyrenees, can overturn the system only feebly, but is effective in synchronizing somehow what happens in the Biscay Bay and the Northwestern Mediterranean. I mean that the years in which atmospheric circulation is more intense, Atlantic superficial and relatively warm water accumulates in the surface of the Bay of Biscay and the continuation of the same pattern of atmospheric circulation results in a more strong upwelling in the Gulf of Lion.

Such pluriannual fluctuations in open waters were observed and recorded by Le Danois (1925, 1943), and confirmed by the associated shifts along the respective shores in the distribution of coastal life, both in French Brittany (approximately in the direction of meridians) and Spanish Galicia refereed to such fluctuations as "marine transgressions" a way of speaking that I find more appropriate than referring to them in the ponderous expression of "El Niño and La Niña"- like phenomena".

The times at which the atmospheric transport from West to East, along the Pyrenees, is more important, allow for surface water of relatively higher temperature to accumulate in the Gulf of 
Biscay and at such times warm water fishes, like dolphin (Coryphaena) are found there. In the same years upwelling is more intense in the Gulf of Lion, along the Catalan-French coast, and deep water organisms like the Mediterranean krill Meganyctiphanes, large colonies of Pyrosoma, and small bathypelagic fishes approach surface along the Western coast of the Gulf of Lion, as South as to the latitude of $42^{\circ} \mathrm{N}$.

In NW Mediterranean the offshore current goes $\mathrm{NE}$ and its position and intensity shifts, as mentioned, in a way that the seasons in which it is particularly strong approaches the coast, at the latitude of Palamós $\left(42^{\circ} \mathrm{N}\right)$, encroaching in the space in other times occupied by the coastal current. The dominant northeastbound directed current has been well recognized by Ovchinnikov (1966) and LePrieur $(1979,1981)$ and the last author adds interesting information about the life that it carries along. In the space in which the current hits the Ligurian coast, where water should ascend, Italian observers have signaled repeatedly the presence of small bathypelagic fishes, being stranded on the beaches with dilated and extruded bladders, as should be expected in specimens forced or pushed up by ascending water. This could serve as an abridged description of the scenario of the NW Mediterranean, an area relatively productive (above 70 and even close to $100 \mathrm{~g}$ of assimilated C per $\mathrm{m}^{2}$ and year), with the fluctuations to be expected in such situations.

I suppose that the minute cyanobacteria in our plankton do not contribute much to the total primary production of our seas. This is one aspect in the subject of general factors of productivity in the NW of Mediterranean that should help to draw the appropriate scenario in which to place recent research on the tiny cells of cyanobacteria in the area, as part of the general interest aroused by their recognition, mass evaluation and significance. Recently The Institut océanographique, Monaco (Charpy and Larkum, 1999) has produced a special publication about the subject, and more papers have been published and are appearing concerning the Western Mediterranean.

Experimental work with Chlorella cultures by Maldonado et al. (1974) has shown how nitrate reductase of this green unicellular alga can operate alternatively also as a reducing agent, that is as a regulator. Thus, it could be expected that the reducing environment, expressed by the reduction of nitrate to nitrite just indicates that photosyn- thetic activity is particularly effective, in conditions where no phosphate is available for synthesis of genuine living material. A "healthy" activity of the "valve" in the pelagic domain could ameliorate the eventual "greenhouse problem". The effectiveness of the top layers of the oceans as a valve would be related to the ratio, concerning the cycle of nitrogen, $f=$ (new production) $/($ recycled production). The value of this index falls ordinarily between 0.1 and 0.3 ; this might be considered as relatively low. Its meaning could be that the increase of extant and eventually dormant populations are limited by other elements, I tend to believe that the principal factor might be the availability of phosphorus. The ubiquity of small green cells is both, an indicator of the general oligotrophic condition of the sea, adscribable ordinarily to lack of phosphorus. (I do not want to enter the discussion about other possible limiting elements. The Mediterranean, by the way, gets lots of iron from the Sahara, but remains in the class of oligotrophic waters.)

Anyway, maps that show the distribution of nitrite provide interesting hints about the events past and present going on at sea, in relation with primary productivity. Given such living conditions, the observer is amazed at the vitality and persistence of such small organisms as the chlorophyll bearing protokariota, of their capacity to remain alive in a state of apparently suspended animation, that makes or allows for their immediate availability if any opportunity for restarting active life presents itself. Their smallness assures them indefinite persistence in any level of water and their immediate availability. They provide a damping background for nutrients. Remarkable might be also their prospective symbiotic value in relation with other elements in the planktonic world. All this returns me -full cercle- back to the times in which I found empirically that the pigment index in the form of the ratio between absorption at two wavelengths, actually 430 and $665 \mu \mathrm{m}$ was a good indicator of the availability of phosphorus and the growth of particular kinds of phytoplankton.

Finally, I have had privileged access to the contribution by Codispoti and coworkers that increased my sense of wonder about the net direction and amount and ways of transfer of reducing power between the terrestrial and the oceanic parts of the biosphere along the history of the Earth and left me wondering how it could imprint evolution of life in our planet. 


\section{REFERENCES}

Including papers relevant in relation with the subject

Bates, M. - 1960. The forest and the sea. Time Inc., New York.

Blasco, D. - 1971. Acumulación de nitritos en determinados niveles marinos por acción del fitoplancton. Tesis doctoral, Universidad de Barcelona.

Broecker, W.S. and T.-H. Peng. - 1984. Gas exchange measurements in natural systems. In: W. Brutsaert and G.H. Jirka (eds.), Gas Transfer at Water Surfaces, pp. 479-493. D. Reidel Publ., Co., Dordrecht, etc.

Charpy, L. and A.W.D. Larkum (eds.) - 1999. Marine Cyanobacteria. Bull. Inst. Océanogr. Monaco, $\mathrm{N}^{\circ}$ special 19: 1-196.

Codispoti, L.A., J.A. Brandes, J.P. Chistensen, A.H. Devol, S.W.A Naqvi, H.W. Paerl and T. Yoshinari - 2001. The oceanic fixed nitrogen and nitrous oxide budgets: Moving targets as we enter the antropocene?. Sci. Mar., 65(Suppl. 2): 85-105.

Cros, M.L. - 2001. Planktonic coccolithophores of the NW Mediterranean. Ph D Thesis, Universitat de Barcelona, Barcelona.

Dandonneau, Y. - 1999. Introducing a series of papers by several French authors (Raimbault; Blain, Tréguer and Rodier; André and coll.; Gonky, Chrétiennot-Dinet et al., Liu, Landry, Vaulot, Campbell, and Claustre, Morel et al.), under the general title of "Biogeochemical conditions in the aequatorial Pacific, 19801994", J. Geophys. Res., 104: 3223-3422.

Doré, J.E. and D.M. Karl - 1966. Nitrite distribution and dynamics at station ALOHA. Deep Sea Res., P. II, 43: 385-402.

Erbacher, J., B.T. Huber, R.D. Norris and M. Margey - 2001 Increased thermohaline stratification as a possible cause for an ocean anoxic event in the Cretaceous period. Nature, 409: 325 327.

Gasol, J.M. and P.A. Del Giorgio - 2000. Using flowcytometry for counting natural planktonic bacteria and understanding the structure of planktonic bacterial communities. Sci. Mar., 64: 197-224.

Hagström, A. - 1999. Marine bacterioplankton: live, dead or dormant? Amer. Soc. Limnol. Oceanogr., Aquatic Science Meeting in Santa Fe.

Karner, M.B., E.F. DeLong and D.M. Karl - 2001. Archaeal dominance in the mesopelagic zone of the Pacific Ocean. Nature, 409: $507-510$

Keffer, T. -1985 . The ventilation of the Wold's Oceans: Maps of the potential vorticity field. J. Phys. Oceanogr., 15: 509-523.

Kolber, Z.S., C.L. Van Dover, R.A. Niederman and P.G. Falkows$\mathrm{ki}-2000$. Bacterial photosynthesis in surface waters of theopen ocean. Nature, 407: 177-179.

Lang, B.M., T. Rujan, W. Martin and R. Croteau - 2000. Isoprenoid biosynthesis: The evolution of two ancient and distinct pathways across genomes. Proc. Nat. Acad. Sci., 97: 13172-13177.

LeDanois, E. - 1925. Remarques générales sur les transgression atlantiques. Cons. Perm. intern. Expl. Mer., Rapp. Proc. verb. Réunions, 35: 5-11.

LePrieur, L. - 1979. Structures hydrologiques, chimiques, biologiques, dans les bassin liguro-provençal. Rapp. Comm. Inter. Mer. Médit., 25/26: 75-76.
LePrieur, L. - 1981. Héterogénéité spatio-temporelle dans le bassin liguro-provençal. Rapp. Comm. Inter. Mer Méditerranée, 27: 77.

Lomas, M.W. and P.M. Glibert - 2000. Comparisons of nitrate uptake, storage, and reduction in marine diatoms and flagellates. J. Phycol., 36: 909-913.

Luyten, J.R., J. Pedlosly and H. Stommel - 1983. The ventilated thermocline. J. Phys. Oceanogr., 13: 292-309.

Maldonado, J.M., M.C. Pueyo and A. Chaparro - 1974. Propiedades reductoras de la nitrato reductasa del alga Chlorella. Rev. Real Acad. Ciencias. Madrid, 68(6): 633-642.

Margalef, R. - 1958. Temporal succession and spatial heterogeneity in phytoplankton, In: A.A. Buzzati-Traverso (ed.), Perspectives in Marine Biology, pp. 323-349. University of California Press, Berkeley and Los Angeles.

Margalef, R. - 1985. Environmental control of the mesoscale distribution of primary producers and its bearing to primary production in the Western Mediterranean. In: M. Moraitou-Apostolopoulos and V. Kiortsis (eds.) Mediterranean Marine Ecosystems, pp. 213-229. Plenum Press. New York and London.

Minas, H.J. and F. Blanc - 1970. Production organique primaire au large et près des côtes méditerranéennes françaises (juin-juillet 1965), influence de la zone de divergence. Téthys, 2: 299-316.

Morán, X.A.G., I. Taupier-Letage, E. Vázquez-Domínguez et al. 2001. Physical-biological coupling in the Algerian Basin (SW Mediterranean): Influence of mesoscale in stabilities on the biomass and production of phytoplankton and bacterioplankton. Deep-Sea Res., I, 48: 405-437.

Ovchinikov, I.N. - 1966. Circulation in the surface and intermediate layers in the Mediterranean. Okeanologia. Moscú, 6: 48-59.

Pedrós-Alió, C., J.-I. Calderón-Paz, J.J. Guixa-Boixareu, M. Estrada and J.M. Gasol - 1999. Bacterioplankton and phytoplankton biomass and production during summer stratification in the northwestern Mediterranean Sea. Deep-Sea Res., 1, 46: 9851019.

Platt, T. and W.K.W. Li, (eds.) - 1986. Photosynthetic Picoplankton. Can. Bull. Fish Aqua. Sci., 214: 1-583.

Sournia, A. - 1973. La production primaire planctonique en Méditerranée. Essai de mise à jour. Bull. Et. Comm. Médit., n ${ }^{\circ}$ sp. 5: 1-128.

Stefels, J. - 2000. Physiological aspects of the production and conversion of DMSP in marine algae and higher plants. J. Sea Research, 43: 183-197.

Vollenweider, R.A. - 1968. Scientific fundamentals of the eutroophication of lakesand flowing waters, with particular reference to nitrogen and phosphorus as factors of eutrophication. Organization for Economic cooperation and Development. Paris, DAS/CSI/68, 27, $159 \mathrm{pp}$.

Vollenweider, R.A. - 1969. Möglichkeiten und Grenzen elementare Modelle der Stoffbilanz von Seen. Archiv. Hydrobiol., 66: 1-36.

Weissert, H., J. McKenzie and P. Hochuli - 1978. Cyclic anoxic events in the early Cretaceous Tethys Ocean. Geology, 147151.

Whitton, B.A. and M. Potts - 2000. The Ecology of Cyanobacteria. Their diversity in Time and Space. Kluiver Academic Publishers. 